\title{
Children with Autism Spectrum Disorder in the Mainstream Playground
}

\author{
Llyween Couper \\ PhD candidate, School of Health Sciences, University of Canterbury \\ Dr Dean Sutherland \\ Senior Lecturer and Programme Coordinator, University of Canterbury \\ Dr Anne van Bysterveldt \\ Speech and Language Therapist \& Senior Lecturer, University of Canterbury
}

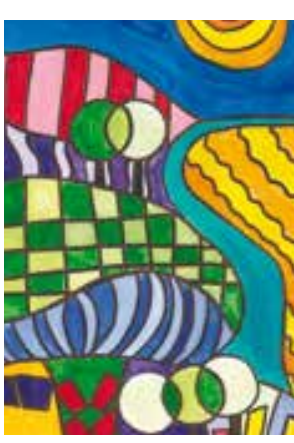

\begin{abstract}
This paper explores the place of the school playground in the lives of children with Autism Spectrum Disorder (ASD). We discuss the physical environment, school systems and practices that support the development of social competence and increased peer interactions for children with ASD in their school playground. Highlighted issues include the importance of play, and the value of the school playground as a curriculum resource with the potential to build a bridge to inclusion for children who experience difficulty developing skills in social interaction, verbal and nonverbal communication and play. Inclusion is more than just placement in regular classrooms. It is about feelings of belonging in the whole school community and that includes being able to participate in the school playground without feelings of anxiety, isolation, or vulnerability.
\end{abstract}

\section{Practice Paper}

Keywords: Autism Spectrum Disorder (ASD), inclusion, playground

\section{INTRODUCTION}

Have you spent time simply observing what is happening in your school playground? Perhaps you will see children participating, contributing and joining in activities with their peers, even playing traditional games that require them to follow rules and manage their behaviour when they are 'out' or feel angry. You may see and hear conflict, teasing, name calling, and students left out, wandering, or sitting on a bench. There may also be opportunities for children to make choices as they think through a challenge. You will possibly hear children communicating their needs, thoughts and feelings, and listening to others as they express theirs. You may see children relating to others, taking turns, joining in to get a job done, helping others, developing skills in cooperation and friendship - the 'Key Competencies' of the New Zealand Curriculum in action.
Take another look at your playground. You may see a child alone, flicking a leaf, continually touching a fence, running around the perimeter of the field, wandering or performing some obsessive behaviour while being watched or shadowed by an adult. You may be looking at the daily playground experience of a child with Autism Spectrum Disorder.

\section{Play: What is it and Why is it so Important?}

Play supports children's brain development in unique ways (Perry, Hogan \& Marlin, 2000). These researchers state that play, more than any other activity, fuels the healthy development of children of all ages and abilities. It is a natural learning tool that develops coordination with both fine and gross motor skills and because it is often fun, it helps to develop emotional wellbeing and stability. According to Pellegrini and Bjorklund (1996) play benefits the ability of all children to pay attention and learn. There is no basis to support assumptions that play should be confined to the preschool years, or that children with ASD do not need to play. Key characteristics of play are that it is fun and also a foundation for building friendships (Doll \& Brehm, 2010). But play is actually hard to define (Sutton-Smith, 2001). Every child knows what it is to play, but the rest of us can merely speculate because spontaneous play is what children do, not what adults organise them to do. Sometimes it is hard to find in school playgrounds. One reason is that some educators need convincing that time playing outside in the school playground matters as much as classroom instruction. Marginalising breaktimes by reducing and over-regulating time for play, especially for children with some form of disability, is limiting an opportunity for interaction with their peer group (Blatchford \& Sharp, 1994). The decision is usually based on an assumption that negative behaviour will decrease or that the expanding curriculum requires more teaching and learning in the classroom. Little mention is made of the possibly detrimental effect this is having on developing skills in social competence, health and wellbeing, especially for those with difficulties with these 
skills such as children with ASD. One of the other opportunities for daily social interactions between children is the walk to school but this is perhaps being taken away for many children by the car ride to and from school (Blatchford, 1998; Pellegrini, 1995). Many children no longer engage in street games or visit parks without adult supervision, limiting another opportunity for peer-initiated interactions. Decisions that devalue time spent playing in the playground do not recognise this as an important time for contact with peers and the social curriculum that exists (Hurni, 2001).

Play often involves physical exercise with benefits that may be more important that just improving physical fitness. Physical exercise interventions have been shown to decrease stereotypy, aggression, offtask behaviour, development, and increase on-task behaviour, academic-responding and appropriate motor behaviour (Lang et al., 2010). Play, physical exercise and leisure activities have benefits which all children, including those with ASD, are entitled to enjoy (Brewster \& Coleyshaw, 2010). The most commonly mentioned activities by children with ASD tended to be those confined to the home; watching television, playing in the garden, computer games and PlayStation. Safety issues arose when activities were suggested that required the children to be away from their parents. Many children played alone yet most said they wanted a friend and wanted to play with friends outside school hours (Brewster \& Coleyshaw, 2010).

Inclusion in leisure activities parallels the situation in education. Inclusion "means more than simply placing a disabled person in a mainstream school and providing extra support. Inclusion demands major changes within society itself and should not be viewed in a vacuum" (Frency \& Swain, 2004, p.169). Improved access to leisure activities for children with ASD and their families would help young people reach their potential as adults. Future research is needed to document the benefits of play and also raise the profile of this aspect of children's lives (Brewster \& Coleyshaw, 2010).

\section{Children with ASD}

In recent years more students with ASD are being educated in mainstream settings rather than segregated environments (White, Scarhill, Klin, Koenig \& Volkmar, 2007). In the UK between 1997 and 2001 there was a $16 \%$ increase of children with ASD attending mainstream schools (Keen \& Ward, 2004). By 2010, the number had increased to $70 \%$ of children in England with ASD attending mainstream schools (Education, 2010). The expectation is for increased opportunities for social interaction and play between children with ASD and their typicallydeveloping peers (Anderson, Moore, Godfrey \& Fletcher-Flinn, 2004). Despite the increased numbers of children with ASD attending mainstream schools very little research has investigated the experiences of children with ASD and their time in their playgrounds (Ingram, Dickerson-Mayes, Troxell \& Calhoun, 2007). Neither has mainstream playground design or equipment been seen as having the potential to increase the frequency of group play and overall social interactions (Yuill, et al., 2007).

Play for children experiencing typical development usually involves some form of interaction with a friend as well as the ability to initiate activities, to share objects and to follow some simple agreed rules without adult intervention. All of these are challenging for children with ASD and unfortunately can often result in social withdrawal, atypical behaviours or one-sided conversations (Marks et al., 1999). The skills to play the simplest game that requires interaction with a peer in the school playground often fill the child with ASD with fear and anxiety (Palmer, 2007). There are many decisions to be made about what to play, how to play, with whom to play and where to play. Active participation in this aspect of the school day is not easy for children with ASD (Brewster \& Coleyshaw, 2010).

Children with ASD experience social difficulties, communicative limitations and a restricted range of interests and behaviours. Social rules such as how and when to look at others, how long to wait when responding to a question, making eye contact, greeting or using appropriate language in different contexts present endless challenges (Ingram et al., 2007; Watson Holton \& Andrew, 1998). Communication difficulties include delay or absence of spoken language as approximately 25\% of children with ASD fail to develop functional or socially appropriate speech (Osterling, Dawson \& McPartland, 2001).

Many researchers remind us that children with ASD are often victims of bullying and the playground is frequently the setting for this unacceptable aggressive behaviour (e.g., Doll \& Brehn, 2010; Rowley et al., 2012). When incidents of negativity are reduced, competent social interactions are prompted, peer acceptance is increased, and friendships form and are maintained. This enables vulnerable students to avoid isolation and loneliness so that they can cope and defend themselves and others from intimidating behaviours. Having friends and siblings around may be the biggest deterrent to becoming a target for bullies according to MacArthur and Gaffney 
(2001) who believe that schools where children have friends are safe places for children with disabilities. A positive playground experience can have an enormous impact on the development of skills in social competence, feelings of belonging, self-esteem and wellbeing for all children including those with ASD (Doll \& Brehm, 2010; Sullivan, 2000; Yuill et al., 2007).

Children with ASD desire social relationships and they can identify feelings of loneliness and exclusion (Brewster \& Coleyshaw, 2010). Despite the challenges in forming friendships they still want to be part of a group of friends and the school playground is where this can happen (Bauminger \& Kasari, 2000). The measure of an effective school playground will be its success in moving these isolated students into the everyday play of their classmates (Doll \& Brehm, 2010).

In order to provide a safe and supportive environment for all children, schools often support children with ASD by providing teacher-aides with the aim of improving academic progress, social and emotional skills. However, some research shows students may receive less teacher attention and become isolated from their peer group (MacArthur \& Gaffney, 2001; Symes \& Humphrey, 2011). The role of teacher-aides in the playground needs clarifying as their presence and practice can reinforce the notion that children with ASD are needy and different (Anderson et al., 2004). Other studies (Alston \& Kilham, 2004; McVittie, 2005) confirm that increased teacher-aide contact can lead to supported students being socially excluded. Employing teacher-aides to track, shadow or protect students with ASD does not always promote their social integration in the playground (Anderson et al., 2004). Their study found that students were rarely encouraged to participate in typical play behaviour or peer interactions and were often discouraged from participating in certain activities (Anderson et al., 2004). Placing the student with ASD during break-time in the library with a computer programme is equally detrimental to gaining skills in social competence. This practice is counterproductive as the more children with ASD are isolated from their peers the more likely they are to develop rigid play routines that lack pretence or social interaction. They need their peers to serve as models in the playground (Hess, 2006).

\section{Play and Children with ASD}

Impairment in play skills such as symbolic, sociodramatic play including imitation and pretend play is a well-documented feature of ASD (Lydon, Healy \& Leader, 2011). The result is that from a very young age children with ASD may demonstrate limited appropriate use of toys and rarely engage in creative, spontaneous or pretend play (Wolfberg, 1995). Instead they tend to engage in repetitive and ritualistic actions with toys. They may line up toys by shape or colour rather than sharing the action with someone else (Hobson, 1993; Paterson \& Arco, 2007; Wolfberg, 1999). This limits their ability to actively participate in their school playground unless some supports and adaptations have been made to the physical environment and decision makers are sensitive to the individual needs of children with ASD.

Compared with other individuals, children with ASD are more likely to have difficulties with motor development including balance, postural stability, gait, joint flexibility, and speed of movement (Lang et al., 2010). In a study that sampled 101 children with ASD across a range of intellectual functioning, 79\% had definite movement impairment and another $10 \%$ were rated as borderline (Henderson \& Sugden, 1992). Deficits may be exacerbated by lack of opportunities to participate in physical activities such as their school playground. Other research shows that children with ASD are actually a special risk group because their sedentary life-style increases the risk of heart disease, diabetes and obesity (WHO, 2002).

The physical environment of the school playground provides valuable steps in a child's development by contact with nature and with peers (Robinson \& Browning, 2011). Educators are reminded of the importance of activities that allow children to climb to develop upper body strength, as well as sliding, swinging, bouncing and spinning structures that are important for vestibular development. Robinson and Browning (2011) support the use of slides, rockers, spring discs and all varieties of swings which can be adapted with straps and cushions for those who need extra support. They suggest that there should be quiet places to which children can escape when they are finding social situations and sensory overload too much. Without somewhere legitimate, children may resort to toilets for security or privacy. To foster independence they like to use signs, cues, interesting pathways and landmarks to identify and provide direction to designated areas. Wheeled toys that need two people to keep them moving help children play together, and to keep friends talking and socialising there are shady benches or log shelters for sitting and watching. An ecological approach such as this, expects that changes will enable the environment to accommodate the child rather than the child changing to fit the environment which is a lingering example of the medical model associating disability with deviance and difference (Oliver, 1992). 
The mainstream playground should be a positive learning place for play. Children with ASD need time in the playground as this is where many aspects of language are acquired including non-verbal cues, turn-taking, joint attention and the regulation of behaviours through requesting and other social behaviours (Terpstra, Higgins \& Pierce, 2002). More intensive instructional support may be needed but there is evidence that children with ASD can be taught to interact socially with their peers (Campbell, Schopler, Cueva \& Hallin, 1996; Green, 1996; Kohler, Anthony, Steighne \& Hoyson, 2001; Lovaas \& Smith, 1989). In their mainstream school playground they should engage in more adaptive play behaviour, learn through modelling, imitation and observation than in any other setting (Lovaas \& Buch, 1997).

Instruction in play skills for children with ASD can encourage social interactions and improve language, social skills and cognitive functioning (Bates, 1979; Dauphin, Kinney \& Strommer 2004; Sigman \& Ungerer, 1984). The developmental readiness of the child needs to be considered when choosing age-appropriate play activities (Lifter, Sulzer-Azaroff, Anderson \& Cowdery, 1993).

A few simple strategies will help inclusion occur naturally:

- The skills to play simple games are taught prior to time in the playground.

- Some specific skills that are required to play popular games that allow interaction with peers are included in Individual Educational Plans.

- Teachers seek opportunities to prepare peers to include the child with ASD in their playground activities (buddy programmes, Circle of Friends, mentoring programmes).

- Forward planning occurs providing for some quiet time activities for the child with ASD who may need solitude as well as social contact.

- Teacher-aides and teachers have shared goals around student independence so that teacher-aides do not get in the way of friendship or interaction opportunities with peers.

Some research has shown that higher levels of play such as symbolic play can be learned. A variety of behavioural techniques have established, increased and improved play skills in children with ASD. Two prominent methods are Pivotal Response Training and Video Modelling (Lydon et al., 2011; Stahmer, Ingersoll \& Carter, 2003). Improvements in spontaneous communication and play during free time was noted by Carr and Felce (2007) after only 15 hours of Picture Exchange Communication System (PECS) training. Not only were there changes in the interactions between the students but also their teachers who decreased their pre-emptive communications, increasing opportunities for children to initiate communication. Play with toys and joint attention improved during free play sessions as well as increased social interactions with peers at the schools (Kravits, Kamps \& Kemmerer, 2002). Schoen \& Bullard (2002) found that seven students with autism who functioned in isolation during the whole recess period noticed the social interaction skills of their peers when teachers prompted them by simply asking 'What are the other children doing?' Group games were taught to all students including same-aged peers. This research concludes that interaction between children with ASD and their same-aged peers in the mainstream is essential in developing and fostering social interactions (Schoen \& Bullard, 2002). It also confirms that children with ASD, like many other children, can learn to play.

\section{CONCLUSION}

School playgrounds have been around since the mid1800s but they have never been as important in the lives of children as they are today. Play and places to play, physical exercise and socialisation are fundamental for the health, wellbeing and development of all children. The school playground can still provide all children including those with ASD with a unique opportunity to experience feelings of belonging, friendship, acceptance and inclusion. Not only is the school playground a valuable curriculum resource but also the natural context where children, with a little help from their friends, can build a bridge to inclusion. Time in the school playground can seriously test inclusion. Take another look at your playground - does it pass or are there opportunities for development and support?

\section{REFERENCES}

Alston, J., \& Kilham, C. (2004). Adaptive education for students with special needs in the inclusive classroom. Australian Journal of Early Childhood, 29(3), 24-33.

Anderson, A., Moore, D. W., Godfrey, R., \& FletcherFlinn, C. M. (2004). Social skills assessment of children with autism in free-play situations. Autism, 8(4), 369-385.

Bates, E. (1979). The Emergence of symbols: Cognitive and communication in infancy. New York.: Academic Press.

Bauminger, N., \& Kasari, C. (2000). Loneliness and friendship in high-functioning children with autism. Child Development, 71, 447-456. 
Blatchford, P. (1998). "The state of play in schools." Child Psychology \& Psychiatry Review, 3(2), 58-67.

Blatchford, P., \& Sharp, S. (Eds.). (1994). Breaktime and the school: Understanding and changing playground behaviour. London: Routledge.

Brewster, S., \& Coleyshaw, L. (2010). Participation or exclusion? Perspectives of pupils with autistic spectrum disorders on their participation in leisure activities. British Journal of Learning Disabilities, 39, 284-291.

Campbell, M., Schopler, E., Cueva, J. E., \& Hallin, A. (1996). Treatment of autistic disorder. Journal of American Academy of Child and Adolescent Psychiatry, 35(2), 134-144.

Carr, D., \& Felce, J. (2007). The effects PECS teaching to Phase III on the communicative interactions between children with autism and their teachers. Journal of Autism and Developmental Disabilities, 24, 724-737.

Dauphin, M., Kinney, E. M., \& Strommer, R. (2004.). Using video-enhanced activity schedulesand matrix training to teach sociodramatic play to a child with autism. Journal of Positive Behaviour Interventions, 6, 238-250.

Doll, B., \& Brehm, K. (2010). Resilient Playgrounds. New York: Routledge.

Education, D. F. (2010). Children with special education needs: An analysis. Nottingham UK: DFE Publications.

French, S., \& Swain, J. (2004). Controlling inclusion in education: Young disabled people's perspectives. In J. Swain, S. French, C. Barnes \& C. Thomas (Eds.), Disabling barriers-enabling environments (2nd ed.). (pp. 169-175.). London: Sage.

Green, G. (1996). Early Behavioural Intervention for Autism: What does research tell us? In C. Maurice (Ed.), Behavioural Interventions for Young Children with Autism: A Manual for Parents and Professionals (pp. 29-44.). Austin, TX: Pro-Ed.

Henderson, S. E., \& Sugden, D. A. (1992). The movement assessment battery for children. London, UK: The Psychological Coorporation.

Hess, L. (2006). I would like to play but I don't know how: A case study of pretend play in autism. Child Language Teaching and Therapy, 22(1), 97-116.

Hobson, R. P. (1993). Autism and the development of the mind. Hillsdale: Lawrence Erlbaum Associates.

Hurni, C. (2001). An exploration of the use of breaktimes to promote the social curriculum in secondary schools. Pastoral Care March, 3-8.
Ingram, D. H., Dickerson-Mayes, S., Troxell, L. B., \& Calhoun, S. L. (2007). Assessing children with autism, mental retardation, and typical development using the Playground Observation Checklist. Autism, 11(4), 311-319.

Keen, D., \& Ward, S. (2004). Autistic spectrum disorder: A child population profile. Autism, 8(1), 39-48.

Kohler, F. W., Anthony, L. J., Steighner, S. A., \& Hoyson, M. (2001). Teaching social interaction skills in the integrated preschool: An examination of naturalistic tactics. Topics in Early Childhood Special Education, 21(2), 93-103.

Kravits, T. R., Kamps, D. M., \& Kemmerer, K. (2002). Brief report: Increasing communication skills for an elementary-aged student with autism using the Picture Exchange Communication System. Journal of Autism and Developmental Disorders, 32, 225230.

Lang, R., Koegel, L. K., Ashbaugh, K., Regester, A., Ence, W., \& Smith, W. (2010). Physical exercise and individuals with autism spectrum disorders: A systematic review. Research in Autism Spectrum Disorders, 4, 565-576.

Lifter, K., Sulzer-Azaroff, B., Anderson, S., \& Cowdery, G. E. (1993.). Teaching play activities to preschool children with disabilities: The importance of developmental considerations. Journal of Early Intervention, 17, 139-159.

Lovaas, O. I., \& Buch, G. (1997). Intensive behavioural intervention with young children with autism. In N.N. Singh (Ed.), Prevention and Treatment of Severe Behaviour Problems: Models and Methods in Developmental Disabilities. Pacific Grove,CC. : Brooks/Cole.

Lovaas, O. I., \& Smith, T. (1989). A comprehensive behavioural theory of autistic children: Paradigm for research and treatment. Journal of Behaviour Therapy and Experimental Psychiatry, 20(1), 17-29.

Lydon, H., Healy, O., \& Leader, G. (2011). Comparison of video modelling and pivotal responses training to teach pretend play skills to children with autism spectrum disorder. Research in Autism Spectrum Disorders, 5, 872-884.

MacArthur, J., \& Gaffney, M. (2001). Bullied and teased or just another kid? The social experiences of students with disabilities at school. Wellington: New Zealand Council for Educational Research. 
Marks, S. U., Schrader, C., Levine, M., Hagie, C., Longaken, T., \& Morales, M. (1999). Social skills for social ills: Supporting the social skill development of adolescents with asperger's syndrome. Teaching Exceptional Children, 32(2), 56-61.

McVittie, E. (2005). The role of teaching the assistant: An investigative study to discover if teaching assistants are being used effectively to support children with special needs in mainstream schools. Education 3-13: International Journal of Primary, Elementary and Early Years Education, 33(3), 26-31.

Oliver, M. (1992). "Intellectual masturbation: A rejoider to Soder and Booth." European Journal of Special Needs Education, 7(1), 20-28.

Osterling, J., Dawson, G., \& McPartland, J. (2001). Autism (3rd ed.). New York: John Wiley \& Sons.

Palmer, N. (2007). Making friends on the playground when you have autism spectrum disorder. Downloaded from: www.asdconsultancy. com/2007/03/making -friends-

Paterson, C. R., \& Arco, L. (2007). Using video modeling for generalizing toy play in children with autism. Behaviour Modification, 31, 660-681.

Pellegrini, A. (1995). School recess and playground behaviour: Educational and development roles. Albany, NY: State University of New York Press.

Pellegrini,A. D., \& Bjorklund, D. F. (1996). The place of recess in school: Issues in the role of recess in children's education and development. Journal of Research in Childhood Education, 11, 5-13.

Perry, B., Hogan, L., \& Marlin, S. (2000). Curiosity, pleasure and play: A neurodevelopmental perspective. The HAAEYC Advocate, June 15.

Robinson, F., \& Browning, L. (2011). Naturally inclusive - A new approach to design for play. Winchester: Learning Through Landscapes.

Rowley, E., Chandler, S., Baird, G., Simonoff, E., Pickles, A., Loucas, T. \& Charman, T. (2012). The experience of friendship, victimization and bullying in children with autism spectrum disorder: Associations with child characteristics and school placement. Research in Autism Spectrum Disorders, 6(3), 1126-1134.

Schoen, S. F., \& Bullard, M. (2002). Action research during recess. A time for children with autism to play and learn. Teaching Exceptional Children, 35(1), 36-39.

Sigman, M., \& Ungerer, J. A. (1984). Cognitive and language skills in autistic, mentally retarded and normal children. Developmental Psychology, 20, 293-302.
Stahmer, A. C., Ingersoll, B., \& Carter, C. (2003). Behavioural approaches to promoting play. Autism, 7, 401-413.

Sullivan, K. (2000). The anti-bullying handbook. Auckland: Oxford University Press.

Sutton-Smith, B. (2001). The ambiguity of play. Harvard University: First Harvard University Press.

Symes, W., \& Humphrey, N. (2011). School factors that facilitate or hinder the ability of teaching assistants to effectively support pupils with autism spectrum disorders (ASD) in mainstream secondary schools. Journal of Research in Special Educational Needs, 11(3), 153-161.

Terpstra, J. E., Higgins, K., \& Pierce, T. (2002). Can I Play?: Classroom-based interventions for teaching skills to children with autism. Focus on Autism and other Developmental Disabilities, 17(2), 119-127.

Watson, M., Holton, D., \& Andrew, S. (1998). Children with autism: Suggestions for teaching in the inclusive classroom. Dunedin: Donald Beasley Institute Inc.

White, S. W., Scarhill, L., Klin,A., Koenig, K., \& Volkmar, F. R. (2007). Educational placements and service use patterns of individuals with autism spectrum disorders. Journal of Autism and Developmental Disorders, 37, 1403-1412.

WHO. (2002). The world health report, reducing risks, promoting healthy life. Copenhagen: World Health Organization.

Wolfberg, P. (1999). Play and imagination in children with autism. New York: Teachers College Press.

Wolfberg, P. (Ed.). (1995). Enhancing children's play. New York: Delmar.

Yuill, N., Streith, S., Roake, C., Aspden, R., \& Todd, B. (2007). Brief report: Designing a playground for children with autistic spectrum disorder - Effects on playful peer interactions. Journal of Developmental Disorders, 37(1192-1196.). 


\section{AUTHOR PROFILES}

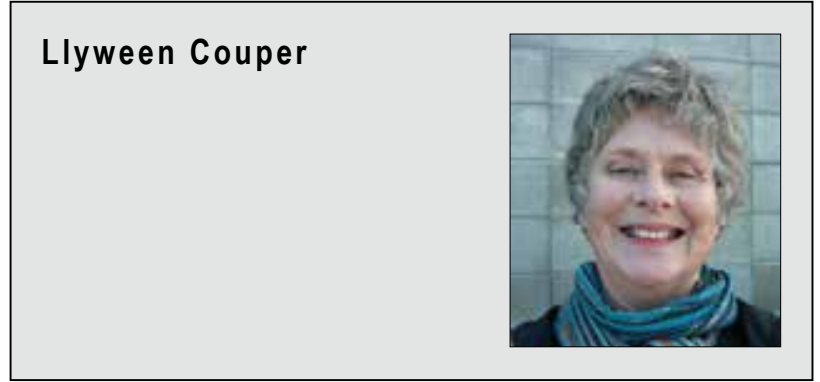

Llyween Couper is a $\mathrm{PhD}$ candidate in the School of Health Sciences at University of Canterbury. The focus of her study is finding the preferred communication choices of nonverbal children with Autism Spectrum Disorders. Part of this study will explore the experiences of the participants in their mainstream playgrounds. In 2013 the findings will be presented at the Disability in Education Conference in Christchurch and at the International Association of Special Education in Vancouver. The paper is titled Too Autistic to Play? The Playground as a Bridge to Inclusion.

Prior to her PhD study Llyween was an RTLB in the Mairehau Cluster and during a Teacher's Sabbatical designed and trialled A Practical Guide to Conducting a Playground Audit. The results from trialling the Audit titled Putting Play Back into the Playground was presented at The International School Psychology Association Conference in Dublin in 2010.

\section{Email:}

Ilyween.couper@pg.canterbury.ac.nz

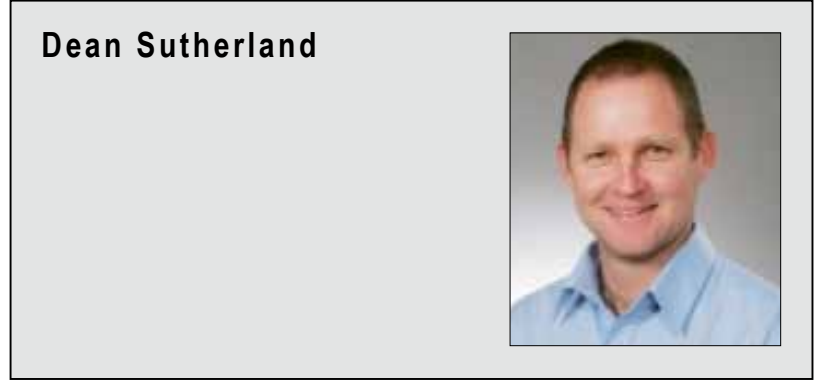

Dr Sutherland is a senior lecturer in the School of Health Sciences Centre and College of Education at the University of Canterbury, Christchurch, New Zealand. His research interests include Deaf Education, Autism Spectrum Disorder, communication between adults and children, and the use of augmentative and alternative communication by children and adults with significant communication difficulties.

\section{Email:}

Dean.Sutherland@canterbury.ac.nz

\section{Dr Anne van \\ Bysterveldt}

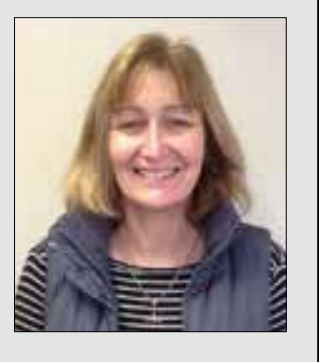

Dr Anne van Bysterveldt is a Speech and Language Therapist and senior lecturer in Developmental Disabilities in the School of Health Sciences, University of Canterbury. Her research focuses on facilitating speech, language and literacy development in young children with developmental disabilities and understanding the home and school environments in which this development occurs. Special interests include the provision of evidence-based therapy for children with Down Syndrome, the importance of early intervention for children with developmental disabilities and the relationship between spoken and written language development in young children with developmental disabilities. Dr van Bysterveldt is coordinator of the Post Graduate Diploma in Specialist Teaching- Early Intervention endorsement.

Email:

anne.vanbysterveldt@canterbury.ac.nz 